\title{
Metric House Address Generation with Semi-automatic Geospatial Web based Technology
}

\author{
Dr. Bhoj Raj Ghimirea,b, *, Bijaya Maharjan ${ }^{\mathrm{c}, *}$, Shakti Shrestha ${ }^{\mathrm{d}}$, Sanil Nakarmi ${ }^{\mathrm{d}}$ \\ a,b bghimire@nou.edu.np, ${ }^{\mathrm{c}}$ bijay.mrjan@gmail.com \\ ${ }^{a}$ Faculty of Science, Health and Technology, Nepal Open University, Lalitpur, Nepal \\ ${ }^{b}$ Science Hub Nepal, Kathmandu, Nepal \\ ${ }^{c}$ Lumbini International Academy of Science and Technology, Lumbini Buddhist University, Lalitpur, Nepal \\ ${ }^{d}$ Perigee Informatics Pvt. Ltd., Chabahil, Kathmandu, Nepal
}

\begin{abstract}
Majority of the old and unplanned cities of the developed countries and fast-growing irregular and unplanned cities in the developing countries have no static address in their buildings. Some technologies like what 3 words, plus codes, six-point maps exist but they work good only when the parcel size is bigger. The cost of assigning the address by manual survey is very costly. Leveraging the availability of the high-resolution satellite imagery and geospatial technology, a cost effective, reliable and semi-automatic system is developed for generating and maintaining the metric house addressing system using open-source software. An interactive and easy-to-use web-gis based application is developed and implemented in a municipality of western Nepal and the result was cross validated with the field-based address. It could generate address to all the building footprint provided with $100 \%$ accuracy in identifying the associated road, side of the building and with a very negligible variation in distance of 2 meters. This application can be used for maintaining not only the building footprint, their address and road but it can also store non-spatial attribute of the building like business entities, tax related information, household survey and many more. The application can be a major milestone for the implementation of e-government services, e-commerce activities and can be the baseline information for smart city. The system can be applied seamlessly to any cities of the other parts of the world.
\end{abstract}

Keywords: Metric House Address; Geospatial; Web-application; Remote Sensing, e-Governance

* Corresponding Authors

\section{Introduction}

A city is a combination of building and transportation with the management of various utility services, land use pattern and communication between large human settlement. The buildings are the ultimate destination for various purpose such as postal delivery, product distribution and delivery, utility management, navigation system for taxi, ambulances and fire brigades, municipal service activities and efficient tax collection system etc. Hence, it is necessary to have a convenient, logical, and consistent addressing mechanism for a building (house) so that government, commercial delivery servicemen and public can promptly locate exact address (Rebolios, Sevilleno, Tongalamos, \& Novabos, 2016). As the matter of fact, buildings are accessed via road. So, road profiling and their coding and inventory management is strongly associated with the buildings for convenient routing and navigation.

The first street numbering systems were applied in the 18th century across Europe for the purpose of administrative tasks and mail delivery service (Porter, 1998). Likewise, the first house address system was 
operated on street-based addressing approach in many countries of United States and United Kingdom. The next address system was implemented initially in Korea on area-based addressing approach. Later on, hybrid addressing system, a combination of both street and area-based addressing approach is on operation for house addressing system (Choi, Park, \& Lee, 2018). There are handful number of addressing systems initiated and being practiced worldwide. What3words $(w 3 w)$ generates a 3-word address for any given location. It's a handy and easy-to-remember addressing system but with a major fall side: two locations adjacent to each other will have totally different codes and there is no way to understand that they are closer. Google has recently come up with Plus Code initiative where a given location is coded with some combination of alpha numeric characters. This is a great initiative specially developed and embedded with the google map services in smart phones but again multiple houses within a small buffer may get the same code. A widely used method provides a unique number to each building along street or area in a sequential order and block, but not in distance approach (Clodoveu, Fonseca, \& Borges, 2003). These systems work good for preplanned cities, where all the plots associated with streets are occupied with buildings and constructed in the same way with less modification and where parcel area per building is generally bigger. However, the implementation of such systems is very challenging in the unplanned old cities where the settlements are not planned and are built in a very small parcel area. Another technique is to apply metric addressing system where buildings are given unique numbers as per their metric distance, rounded up to the closest odd or even number, from the starting point of the associated road. The system is applicable in both planned and growing cities, where vacant plot in between building occupied plots turned into a new building will not affect the existing house number flow. So, the metric house numbering system, integrated with odd-even rule is considered as superior addressing system in the world (Clodoveu et al., 2003). However, it is relatively expensive method as a huge resource is needed to measure the distance of each house from the origin of the road.

The geospatial technologies have been able to solve many real world problems in health (Mishra, Ghimire, \& Baral, 2013), urban transport (Peungnumsai et al., 2017), forestry (Ghimire et al., 2017), pandemic situation (Parajuli et al., 2020); (Maharjan et al., 2020) and many more. With the advancement in the remote sensing technologies, we have many satellite sensors providing a very high precision maps of the earth's surface which makes it easier to digitize the objects like buildings, roads and other landmarks in the earth with high accuracy and low cost. This development can be leveraged to solve the addressing problem to a great extent.

Nepal is topographically divided into Himalaya to the north (15\%), the middle hills $(68 \%)$ and the Terai to the south (17\%) with unique geographical diversity and altitudinal variation from 59 meters above sea level to the highest point of 8,848 meters ("Geography of Nepal," 2021). The urban area of Nepal was 18.2\% in 2014 . Nepal is one of the ten fastest urbanizing countries and it will remain the same for the period of 2014-2050 with projected annual urbanization rate of $1.9 \%$ (Bakrania, 2015). Rapid unplanned growth of buildings within various existing and growing cities makes it complicated to implement a sequential house address numbering without disturbing the existing number flow. In early 2000, Kathmandu Metropolitan City had practiced the addressing system based on paper-based cadastral map with manual measurement of doorway location on the street, which could not get continuity due to problem in public utilization and unorganized database (KMC and EU, 2000). Likewise, Lalitpur metropolitan city has piloted the digital metric house addressing system using digitization of high resolution $(0.32 \mathrm{~m})$ stereo satellite images by employing the photogrammetry technique followed by assign of numeric distance value from street start junction to doorway of each building, is a good initiation on addressing system (Poudel \& Shrestha, 2021). However, the features information needed for base map and addressing system were collected from field and later feed into the autoCAD software. The whole data structures were finally transferred to GIS environment for storing of house numbering in digital format. The process of complete task needed comparatively longer period of time and intensive table as well as field work. 
Department of Urban Development and Building Construction (DUDBC) has issued a guideline for Address System Directory (DUDBC, 2018), which is a step towards the systematic metric house addressing system.

The objective of this research is to develop a cost effective, semi-automatic web gis based technique to generate seamless metric house address under the guidelines of DUDBC-metric house addressing system for both existing dataset and newly constructed building using open-source technologies.

\section{Data}

The major datasets used for the research are existing geometric shapefile of building footprints and road networks which are collected and compiled from Municipal Transport Master Plan (MTMP) of corresponding local authorities. The spatial reference of the data sources used in this research was based on World Geodetic System WGS 1984 (WGS84). The municipal and ward boundary were obtained from Survey Department under Government of Nepal (DoS, 2020). The new buildings constructed after the preparation of MTMP, were digitized from Google Earth. Google Earth is a popular virtual globe software of open access and user-friendly interface that provides realistic and engaging images of the Earth surface of mid and high-resolution satellite and aerial imagery from multiple providers with overall positional accuracy close to $1 \mathrm{~m}$ (Pulighe, Baiocchi, \& Lupia, 2015).

\section{Methods}

Metric house addressing system is a systematic and consistent addressing system where the address is given to each building with reference to cumulative distance measured from starting point of the associated road to the main gate of the building. The number of the building is actually measured distance of the building in meter from start point of associated road segment followed by odd and even rule. So, building code does not necessarily start with a number 1 and moves in sequential order such as 2, 3, 4, 5 and so on. Rather the number is provided as the measure of the distance. The number will not be assigned in fraction but is rounded to its ceiling function. That vacant plot does not get the code however its distance is secured for future address. Even number will be assigned to the building of right side of road and odd number will be assigned to the building of left side. For the house which are connected to the main road with some narrow foot trails an Offset distance is set which is a distance in meter between main road to building plot.

DUDBC has addressed the flow of metric house numbering of various simple to complex city patterns. The flow of metric house number in a simple linear settlement pattern is as per visualized in Fig (1). The vacant plot when turns into building is described in Fig (2) as per different situation. The number will be provided to the building located around crossroad is described in Fig (3) based on the orientation of main entrance of building related to nearest road. 


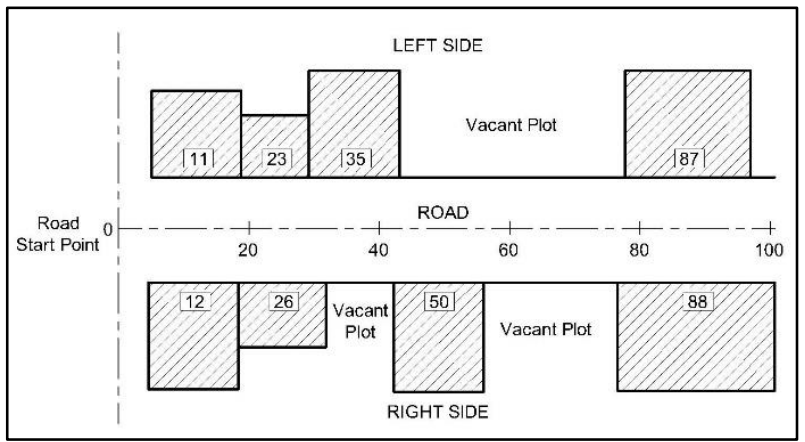

Fig. 1: Linear settlement pattern

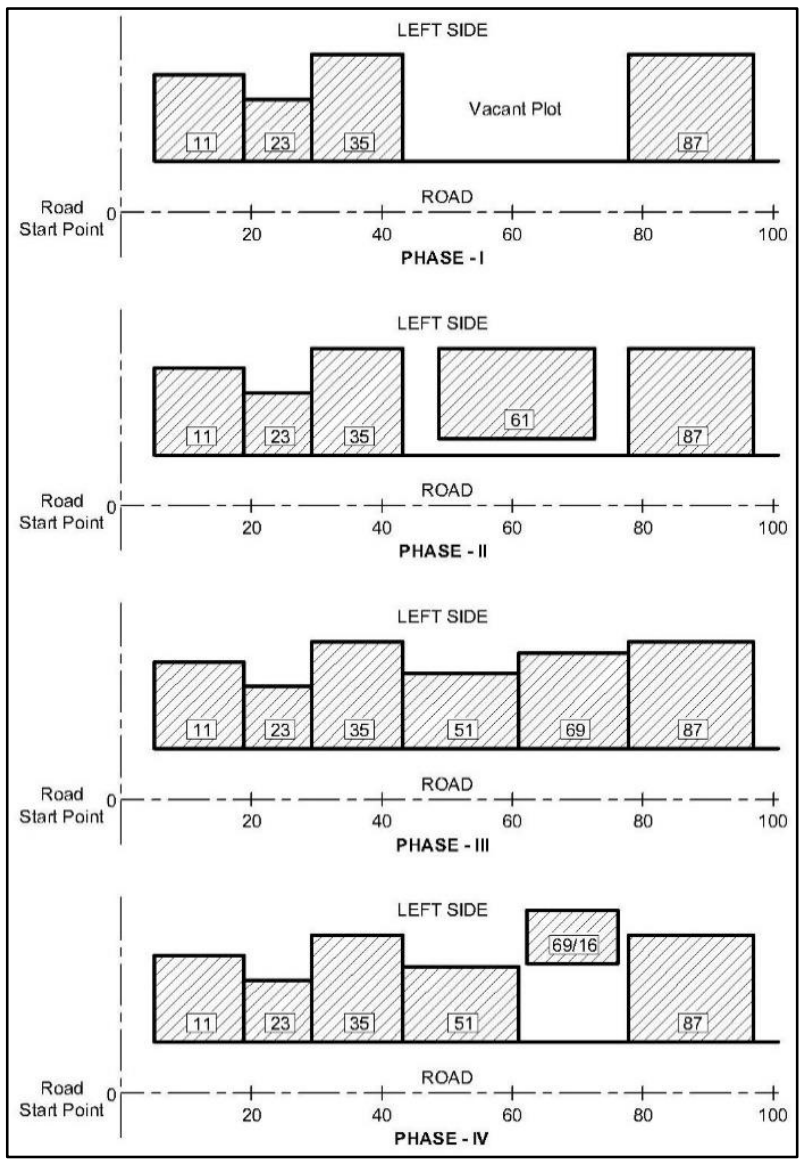

Fig. 2: Vacant plot turns into building 


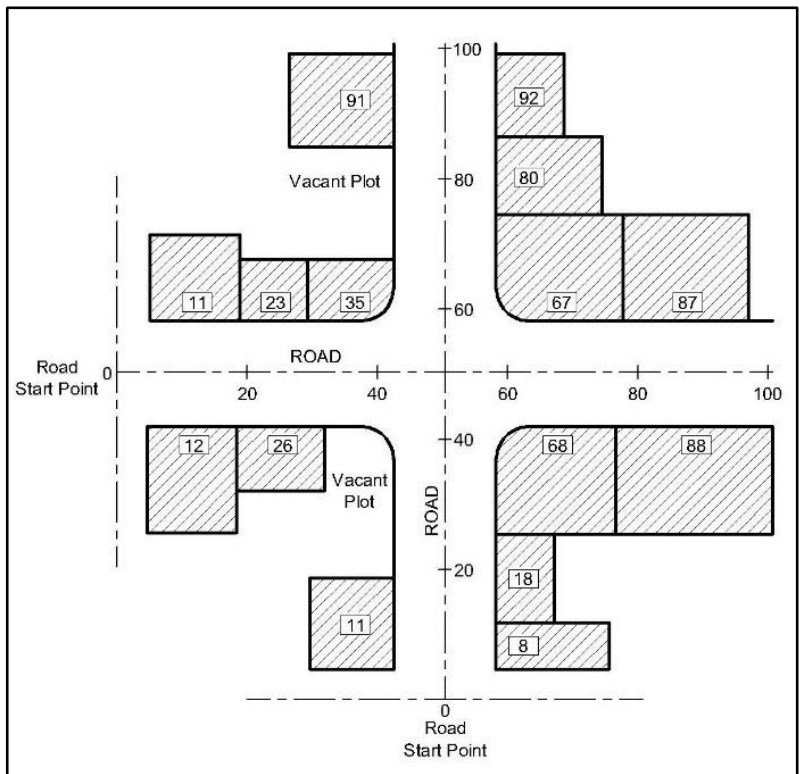

Fig. 3: Building around crossroad

The overall sequential flow of the method adapted is presented in the Fig (4). 


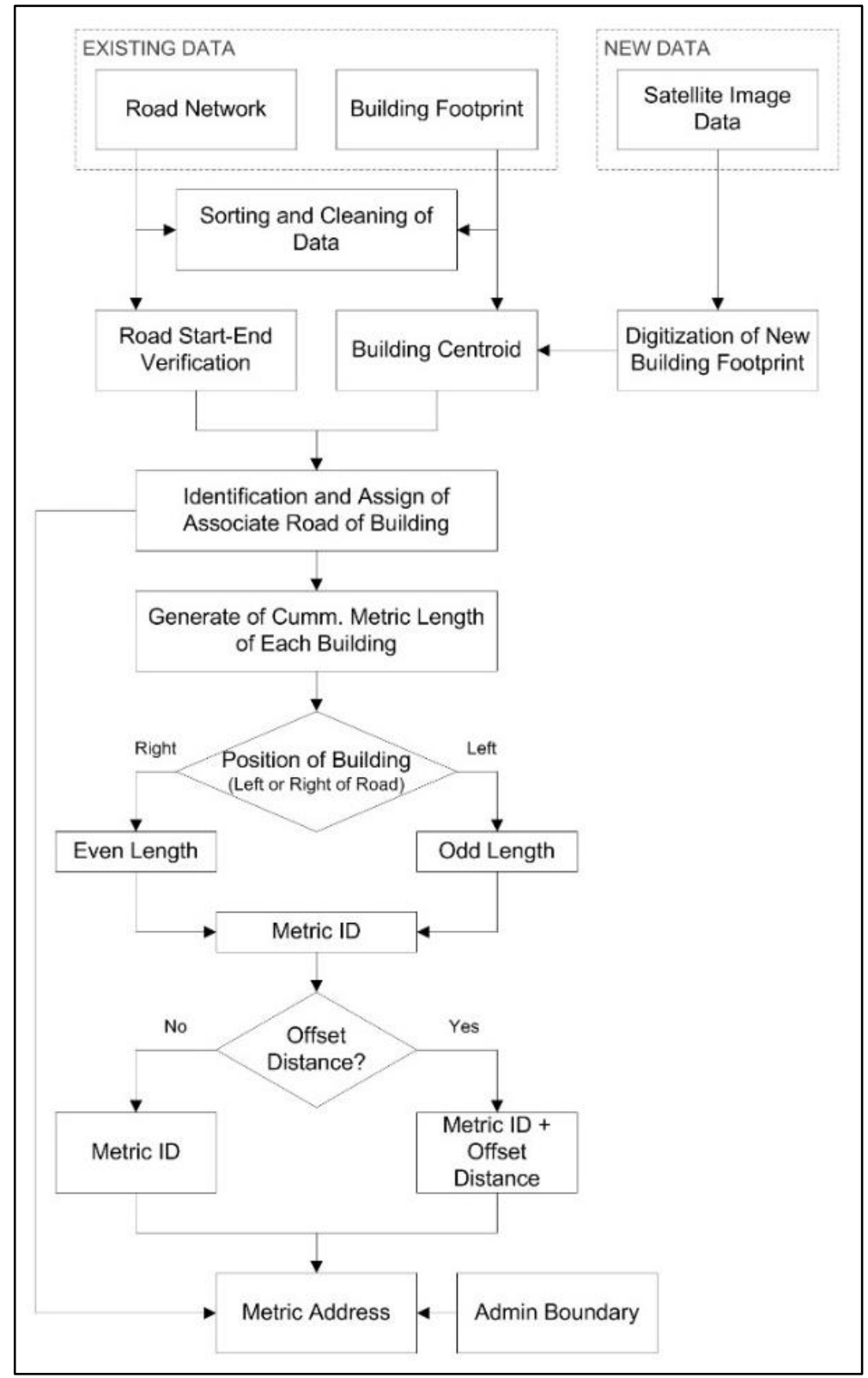

Fig. 4: Flow diagram of metric house address 


\subsection{Road Profile}

Road network is one of the essential components for the generation of metric house number. The municipal road networks are categorized as per their functional hierarchy as National Highway (NH), Feeder Roads (FR), District Roads (DRCN) and Urban roads of various sub-category such as Class A, Class B, Class C and Class D (DoR, 2013) as shown in Table (1). The right-of-way (ROW) of each road category as per respective guidelines are as below.

Table 1: Road Classification

\begin{tabular}{lll}
\hline Road Class & Descriptions & RoW $(\mathrm{m})$ \\
\hline NH & National Highway & 50 \\
FR & Feeder Road & 30 \\
DRCN & District Road & 20 \\
A & Main Collector & 14 \\
B & Other Collector & 10 \\
C & Main Tole Road & 8 \\
D & Other Tole Road & 6 \\
\hline
\end{tabular}

Each building unit is connected with at least one street, followed by measurement of distance of street segment to the building units. So, road should have unique ID, road name, class, code, RoW, width, and surface status. The full code of road comprises the information of province, district, municipality, road category and number of road segment as below in Table (2) and provides base data for house numbering.

Table 2: Road Code Parameters

\begin{tabular}{ll}
\hline Road Full Code: 47603A001 & \\
\hline 4 & Province \\
76 & District \\
03 & Urban / Rural Municipality \\
A & Road Class \\
001 & Sequential Number of Road \\
\hline
\end{tabular}

The orientation of road is also an important factor in measurement of distance. Generally, road alignments are directed from east to west or north to south. The road directed from west to east or eastward, the initial west point of road is considered as start point of road. Whereas road directed from south to north or northward, the initial south point of road is considered as start point of road. The rule is not applicable in all situations such as a dead-end road directed from east to westward or a branch road started from the main road. The research application allows authorized user to define the start and end point of the road alignment for logical and consistent house numbering as shown in Fig (5). 


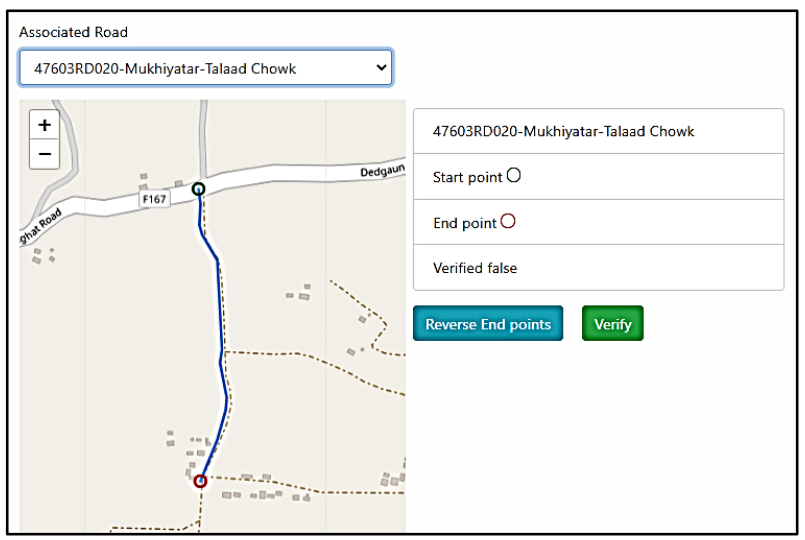

Fig 5: Road Verification

\subsection{Metric House Numbering}

The generation of metric house numbering mainly includes GIS platform, Geo-server and web mapping tools and technologies. The data preparation begins with sorting and cleaning of geojson data of road networks and building footprints for development of geodatabase. The centroids of each building unit are created, from which its nearest road is identified. A buffer distance and associated road can be manually configured through a graphical user interface in case of ambiguity. The position of the building whether it is located left or right side along the associated road alignment was also identified. The cumulative length of each building units (building centroid perpendicular to road) is measured from the start point of respective road alignment in meter as shown below in Table (3). It will escape the vacant plots while measuring length along road alignment. All the building plots may always not directly touch the road alignment. Some building units may have vacant plots or another building in between road alignment and may access via non codable foot trails. So, such building plots may have some length of offset distance from associated road alignment after measuring cumulative length. Such building units include both cumulative length and offset distance separated by "/" as metric house number. The final offset distance includes the deduction of half of RoW of associateed road. The analysis, generation and mapping of house number is implemented using various technologies like geo-server, leaflet, vue, postgresql with postgis and php.

Table 3: Metric House ID

\begin{tabular}{ll}
\hline Building at Right & Building at Left \\
\hline 450 & 451 \\
Even House Number & Odd House Number \\
& \\
$450 / 30$ & $451 / 30$ \\
With Offset distance & With Offset distance \\
\hline
\end{tabular}




\subsection{Metric House Address}

Metric house address is the complete address of each building units comprising of metric house number with its associated road name and additional locational information about respective municipality name and ward number. The generated typical template of metric house address is shown in Table (4). The further information about building ownership, type, use, coverage area etc. are stored in geodatabase and can be updated and viewed as per user need.

Table 4: Metric House Address

\begin{tabular}{c}
\hline Municipality Name - Ward No. \\
Cumm Length / Offset Distance \\
Road Name \\
\hline Baudikali - 2 \\
$\mathbf{4 5 0 / 3 0}$ \\
Gaindakot - Rampur - Maldhunga Road [F167] \\
\hline
\end{tabular}

\section{Validation}

The adopted methodology of metric house addressing system is implemented in Baudikali Rural Municipality for real practice and application validation. Baudikali Rural Municipality is located in Nawalparasi East District of Gandaki Province. The total population of Baudikali Rural Municipality is 15,734 comprising of 2,998 Household (CBS, 2011) in an area of $91.88 \mathrm{Sq}$. Km and further subdivided into 6 wards. The rural municipality is connected via feeder road of Gaindakot - Rampur - Pipaldanda - Maldhunga Road (F167). Other earthen rural roads are developed for connectivity and mobility within rural municipality. As per MTMP, published by Baudikali Rural Municipality, it has 4,295 numbers of building units comprising of 143 road segments with 274 kilometers of road network. The base map visualized the spatial distribution of buildings and road networks within rural municipality as shown in Fig (6) and detail orientation of building with respect to their associated road alignment was visualized as seen in Fig (7) with other non-spatial attributes of the building (Fig 8). 500 houses were randomly chosen, and the system generated address were cross validated with the manual tape and chain method. The result showed $100 \%$ match on the associated road, and side of the building. The metric distance was variable with one or two meters which was due to the variation in the centre of the start point of the road, route followed in manual method versus straight line in the system. However, since the address was calculated as a perpendicular drawn from the centre of the footprint the variation of 1-2 meters still keeps us within the building territory and hence it is least significant in terms of address. 


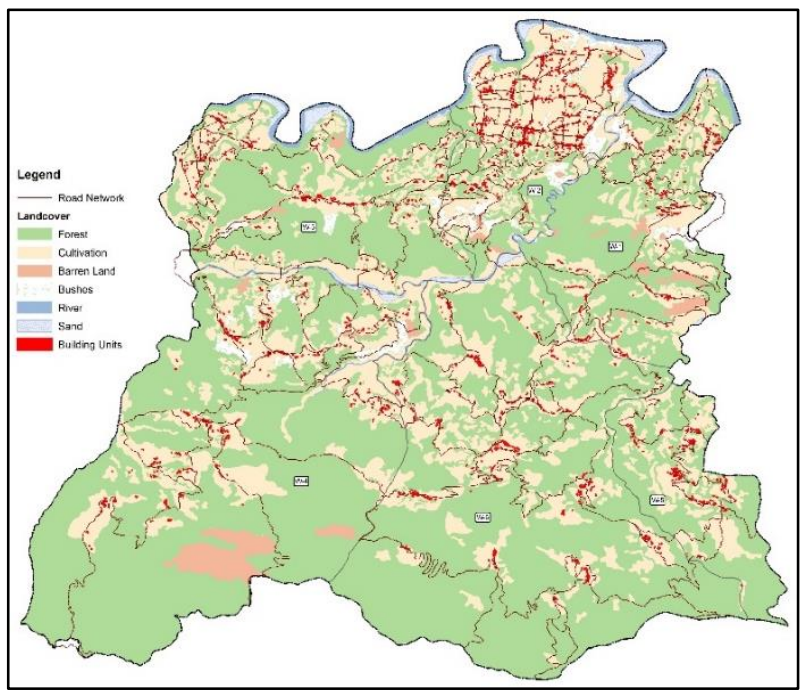

Fig 6: Base map of Baudikali rural municipality

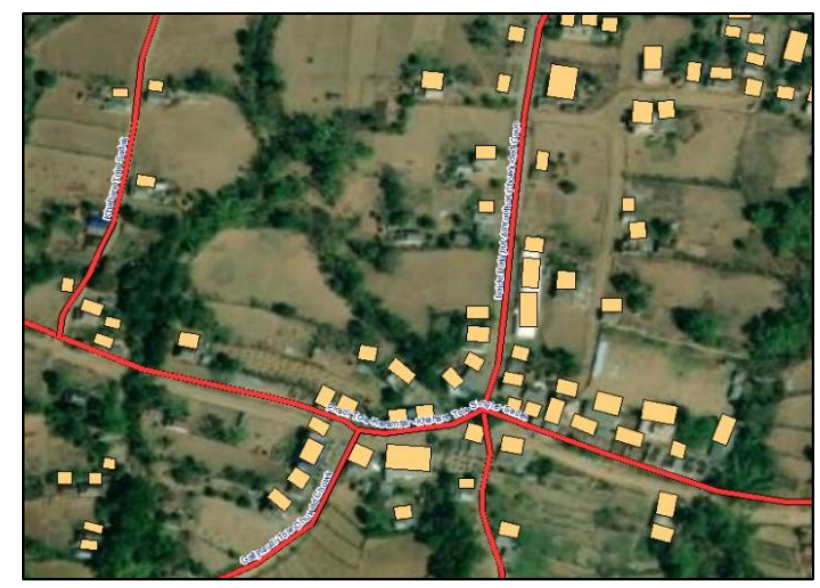

Fig 7: Road network and building footprint 


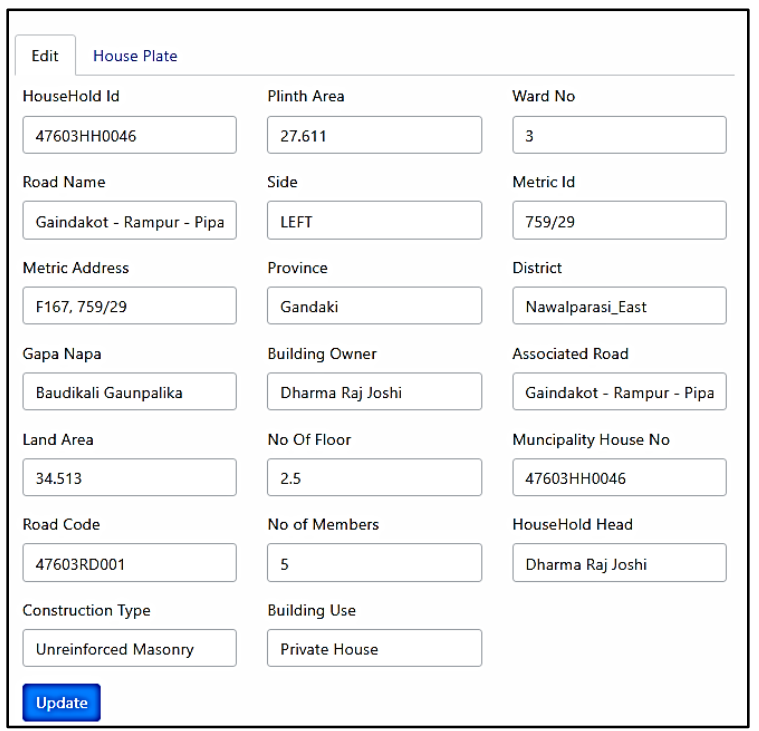

Fig 8: Building information

The metric house id is generated to each building units by following the above-mentioned systematic rules with the integer value of distance followed by odd-even rule from main junction of road to building unit alongwith offset distance if available as shown in Fig (9). The user interface in the web application provides a searching tool so that user could easily find out building according to ascending or descending array of number pattern of specific road alignment. The digital database provides easy access to authorized user to update and modify other non-spatial information of building (like household owner, tax information, building permit information etc.) whenever necessary and retrieve data for various purpose.

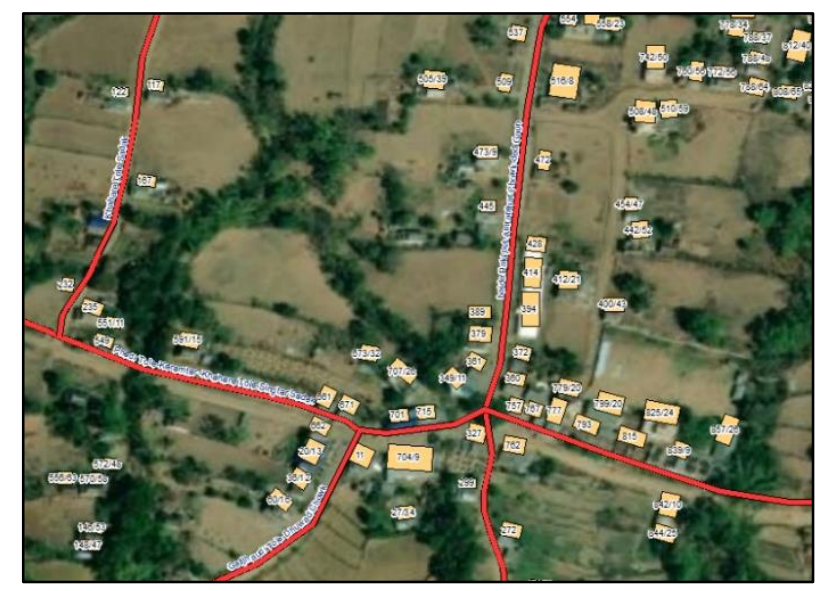

Fig 9: Metric house ID within building footprint 
The automatically generated metric house id combined with associated road name along-with municipality name and ward number for complete metric house address as shown in Fig (10). The authorized user can download and distribute address template to individual building user for the preparation and installation of house address plate to each building units.

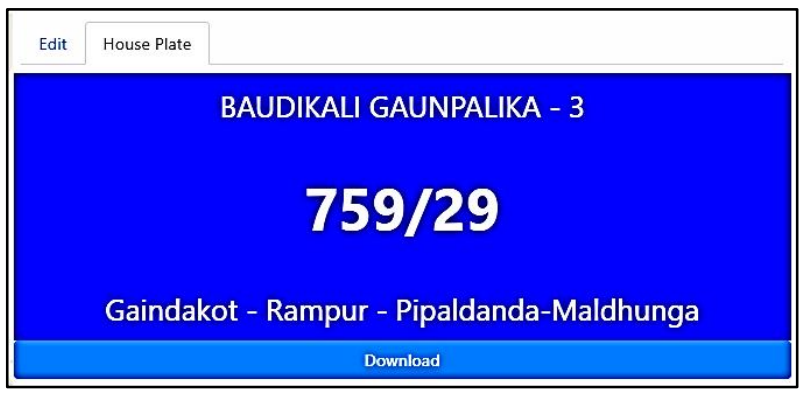

Fig 10: Metric House Address Plate

\section{Results}

The geospatial based metric house address generation is highly complex and challenging task where buildings within cities are expanding rapidly and in irregular pattern. The developed web application of metric house addressing system provides a cost effective and easy to use and maintain digital platform for municipality database. The complex structure of road network can be visualized and maintained with just one-time verification of orientation (start-end) through the platform. The platform provides the geo visualization of spatial distribution of existing building footprint and placement of new building with necessary attribute information. Based on building and its associated road, metric house address is generated to each building. The new address is generated to the vacant plot when transformed into new building without having to re-adjust the existing addresses through a very simple process of uploading the shapefile of the building footprint and setting its associated road. It is so far systematic and consistent way of house address generation and less possibility of false and duplicate address. So, anyone could easily and promptly identify building according to ascending or descending array of number pattern and odd or even value for left or right side of specific road alignment. The complete house address is available to download in pdf format.

\section{Discussion and Recommendation}

Various government and commercial organizations provide services and/or collect revenue such as electricity, water supply, waste collection, building permit, taxation system, has created their own ID or address system to individual building units for the operation of work. There is not proper synchronization of addressing system between them. Individual peoples are confused to provide exact address of their house. Rapid and irregular growth of buildings within cities makes it more complex in house numbering. The geospatial based metric house address system is systematic and consistent way of house address generation. It is effective, reliable and can easily be integrated with other systems of various service provider through application program interface 
(API). This application can easily be integrated with municipal system like taxation, building permit, household survey etc. This paves the way for facility-based tax assessment system in web-gis platform which is thought of but not really been applied in the region.

The metric house address generation system is not only applicable for generation of house numbering, but the unified implementation of system will be helpful for overall municipal planning and major decision-making process. The system is a major infrastructure for e-commerce-governance and a smarter city. The research team is looking forward to implementing it nationwide provided the support from the government and other development partners.

\section{References}

Bakrania, S. (2015). Urbanisation and urban growth in Nepal. GSDRC Helpdesk Research Report 1294. Birmingham, UK. Retrieved from www.gsdrc.org

CBS. (2011). National Population and Housing Census 2011. Central Bureau of Statistics. Kathmandu, Nepal.

Choi, J. H., Park, I. H., \& Lee, J. (2018). Defining the Framework of Address Systems Based on Street-Based Address System in Korea. International Archives of the Photogrammetry, Remote Sensing and Spatial Information Sciences - ISPRS Archives, 42(4/W9), 321-323. https://doi.org/10.5194/isprs-archivesXLII-4-W9-321-2018

Clodoveu, A. D., Fonseca, F. T., \& Borges, K. A. de V. (2003). A Flexible Addressing System for Approximate Geocoding. GeoInfo 2003: Proceedings of the Fifth Brazilian Symposium on GeoInformatics, Campos Do Jordão, São Paulo, Brazil, (October 2003).

DoR. (2013). Nepal Road Standard 2070. Department of Roads. Kathmandu.

DoS. (2020). Shapefile (GIS Data) for Political and Administrative Map of Nepal. Retrieved May 24, 2020, from http://www.dos.gov.np/notice/shapefilegis-data-for-political-and-administrative-map-of-nepal

DUDBC. (2018). Metric Address Directory. Department of Urban Development and Building Construction. Kathmandu, Nepal.

Geography of Nepal. (2021). Retrieved from https://en.wikipedia.org/wiki/Geography_of_Nepal

Ghimire, B. R., Nagai, M., Tripathi, N. K., Witayangkurn, A., Mishara, B., \& Sasaki, N. (2017). Mapping of Shorea robusta forest using time series MODIS data. Forests, 8(10), 384. https://doi.org/10.3390/f8100384

KMC and EU. (2000). Guidelines for Metric Addressing System. Kathmandu Valley Mapping Programme: Integrated Urban Development Programme. Kathmandu.

Maharjan, B., Maharjan, A., Dhakal, S., Gadtaula, M., Shrestha, S. B., \& Adhikari, R. (2020). Geospatial mapping of COVID-19 cases, risk and agriculture hotspots in decision-making of lockdown relaxation in Nepal. Applied Science and Technology Annals, 1(1), 1-8. https://doi.org/10.3126/asta.v1i1.30263

Mishra, B., Ghimire, B. R., \& Baral, D. (2013). Japanese Encephalitis Risk Zone Mapping Using Remote Sensing Data : A Case Study of Mid and Far-Western Part of Nepal. Journal of Remote Sensing \& GIS, 4(2), 47-55.

Parajuli, R. R., Mishra, B., Banstola, A., Ghimire, B. R., Poudel, S., Sharma, K., .. Van Teijlingen, E. (2020). Multidisciplinary Approach to COVID-19 Risk Communication: A Framework and Tool for Individual and Regional Risk Assessment. Scientific Reports, (0123456789), 1-14. https://doi.org/10.2139/ssrn.3634190

Peungnumsai, A., Witayangkurn, A., Nagai, M., Arai, A., Ranjit, S., Ghimire, B. R., ... Ghimire, B. R. 
(2017). Bangkok taxi service behavior analysis using taxi probe data and questionnaire survey. ACM International Conference Proceeding Series, Part F1296, 1-8. https://doi.org/10.1145/3092090.3092117

Porter, R. (1998). London, a Social History. Harvard University Press. London: Harvard University Press.

Poudel, K. P., \& Shrestha, S. (2021). Digital Addressing of Historical City Morphology: The Case of Lalitpur City in Kathmandu Valley, Nepal. Advances in 21 st Century Human Settlements. Singapore: Springer. https://doi.org/https://doi.org/10.1007/978-981-15-5608-1_21

Pulighe, G., Baiocchi, V., \& Lupia, F. (2015). Horizontal accuracy assessment of very high resolution Google Earth images in the city of Rome, Italy. International Journal of Digital Earth, 9(4), 342-362. https://doi.org/10.1080/17538947.2015.1031716

Rebolios, D. B., Sevilleno, D. A., Tongalamos, J., \& Novabos, C. R. (2016). A Usability Test of Four House Numbering Schemes. 8th Industrial Engineering Research Congress, (February 2016). 